\title{
SOROEPIDEMIOLOGIA DA INFECÇÃO PELO VÍRUS DA HEPATITE A EM "MENINOS DE/NA RUA" DE GOIÂNIA-GOIÁS
}

\author{
D.A.O. Queiróz, D.D.P. Cardoso, C.M.T. Martelli, R.M.B. Martins, S.O.B. \\ Porto, M.S.P. Azevedo, A.M.T. Borges e R.R. Daher
}

\begin{abstract}
Um estudo soroepidemiológico, para anticorpos contra o virus da bepatite $A$ (antiVHA total-IgM e IgG), foi realizado no periodo de 1991-1992, em 397 "meninos de/na rua" em Goiânia. Destes, 313 apresentavam vinculo familiar e desenvolviam, em sua maioria, atividades de trabalbo informal, enquanto que 84 não possuíam vínculo familiar e se encontravam na rua ou em Instituições do Governo Estadual. A taxa média de prevalência foi de 90,4\%, variando de $80,0 \%$ a 92,9\%, sem contudo apresentar diferença estatistica significante relativa à idade (7-21). Também não se evidenciou qualquer diferença quando este grupo foi estratificado para presença ou ausência de vinculo familiar ou mesmo quando analisado em relação a outras variāveis sócio-demográficas. Estes dados sugerem que a bepatite $A$ é endêmica na população de baixa condição sócio-econômica da região e que nesta faixa etâria a maioria dos indivíduos jâ adquiriu a infecção. Outras investigações em grupos $e$ camadas sociais diferentes são necessárias affim de parametrar estratégias vacinais em paises subdesenvolvidos.
\end{abstract}

Palavras-chaves: Hepatite A. Soroepidemiologia. "Meninos de/na rua".

O padrão de infecção do vírus da hepatite A (VHA), desde a década passada, vem mudando sobremaneira, restringindo a infecção a grupos de risco em países industrializado ${ }^{23}$, ou mesmo retardando-a para idades mais elevadas em países em desenvolvimento ${ }^{7}$. Contudo, em países subdesenvolvidos, a infecção pelo VHA continua a ser alta na primeira infância, chegando a atingir, por volta dos 10 anos, taxas de prevalência em torno de $90 \%$.

No Brasil, Região Sudeste, um estudo realizado em crianças menores de 11 anos e adultos de baixa renda mostrou prevalências de $75 \%$ e $100 \%$. Já no grupo populacional de nivel médio, de mesma faixa etária, observaram-se $40,3 \%$ e $91,9 \%$, respectivamente ${ }^{17}$. No Rio de Janeiro, uma

\footnotetext{
Laboratório de Virologia, Departamento de Microbiologia do Instituto de Patologia Tropical e Saúde Pública (IPTSP) da Universidade Federal de Goiás, Goiânia, GO.

Financiamento: Pró-Reitoria de Pesquisa e Pós-Graduação (PRPPG) e Conselho de Ciência e Tecnologia do Estado de Goiás (CONCITEG).

Endereço para correspondência: Prof. Divina Aparecida Oliveira Queiróz. Laboratório de Virologia do $\operatorname{Dept}^{\circ}$ de Microbiologia/IPTSP/UFG. R. Delenda Rezende de Melo c/ $1^{a}$ Av., 74001-970 Goiânia, GO.Telefax: (062) 2616414. Recebido para publicação 23/09/94.
}

investigação desenvolvida em duas comunidades urbanas de poder sócioeconômico diferentes (Nova Iguaçu e Niterói), mostrou prevalência de $90 \%$ nas faixas de $11 \mathrm{e}$ 31 anos de idade'. Em outro estudo, realizado em primodoadores, o percentual foi de $97 \%{ }^{22}$. Ainda no Rio de Janeiro, observou-se, em universitários com média de idade de 21 anos provenientes de 5 diferentes cursos da área de ciências biológicas, $38,0 \%$ para os alunos de medicina e $75,8 \%$ para os de enfermagem ${ }^{16}$.

$\mathrm{Na}$ Região Norte (Amazônia), encontrou-se $83,6 \%$ em crianças de 5-9 anos de baixo poder aquisitivo e $100 \%$ nos indivíduos acima de 10 $a_{n o s}{ }^{2}$. Na região Centro-Oeste (Goiânia), observamos $69,7 \%$ em crianças de creches públicas $^{18}$.

Nos últimos 2 anos, poucos estudos soroepidemiológicos sobre o anti-VHA têm sido realizados, provavelmente, porque na maioria dos países esse perfil já é conhecido. Entretanto, com a liberação comercial da vacina inativada e avanços no preparo de outras vacinas, entendemos ser oportuna a retomada desses estudos. Tivemos como objetivos determinar a prevalência do antiVHA total e avaliar fatores de risco sóciodemográficos associados à soropositividade ao VHA em "meninos de/na rua" de Goiânia. 


\section{MATERIAL E MÉTODOS}

Área e Grupo populacional: A pesquisa foi realizada em Goiânia, no período de novembro de 1990 a abril de 1992, em 397 indivíduos de 7 a 19 anos de idade, vinculados, em sua maioria, à Secretaria de Promoção Social do Estado de Goiás através de instituições que atuam no atendimento social da população carente, na faixa da infância/adolescência. Foi adotada a seguinte definição: "Meninos de rua" - menores que perderam o vínculo familiar e portanto, ora vivem nas ruas da cidade, ora são encontrados institucionalizados ( $N=84)$. "Meninos na rua" menores que trabalham na rua e mantêm vínculo com seus familiares e que praticam, na maioria das vezes, atividades de trabalho informal $(\mathrm{N}=313)$.

Não havia registro atualizado sobre o total de "meninos de/na rua" em instituições e órgãos oficiais. Optou-se por triar sorologicamente todos os individuos presentes no momento da visita às instituições. Assim, participaram do estudo 3 indivíduos com idade entre 20 e 21 anos.

Entrevista: Foram registrados, em questionário padronizado, dados de identificação e características sóciodemográficas como: nome do individuo e do responsável, endereço residencial, idade, sexo, escolaridade, vínculo familiar, renda familiar, tipo de moradia, disponibilidade de água tratada, filtro caseiro, rede de esgoto, banheiro com vaso sanitário, história pregressa de hepatite ou ictericia, e período de permanência nas instituições.

Exames sorológicos: Foram coletados $5 \mathrm{ml}$ de sangue e as amostras séricas foram separadas e estocadas a $-20^{\circ} \mathrm{C}$ até a realização dos testes sorológicos. Para os "meninos na rua", foi obtida permissão das instituições. Para os adolescentes sem vínculo institucional e sem família, a solicitação foi feita de forma individual, sendo que a coleta de sangue foi realizada após consentimento expresso.

Todas as amostras séricas foram processadas, durante o primeiro semestre de 1992, pelo teste imunoenzimático (ELISA) ${ }^{20}$, do tipo competitivo, para deteç̧ão do marcador de infecção pelo VHA (anti-VHA total). Para realização deste teste, preparou-se o antígeno do VHA através do cultivo da amostra HM175 em células FRhK-4 e os demais imunobiológicos foram cedidos pelo Centro de Referência Nacional para Hepatites Virais Fiocruz/Biomanguinhos - Rio de Janeiro.

Análise dos dados: Estimativas de Risco (Razão de prevalência) foram calculadas com intervalo de $95 \%$ de confiança e testes de significância em nível de 5\%. Testes de $\mathrm{x}^{2}$ para testar diferenças nas frequências de distribuições, $\mathrm{x}^{2}$ para tendências e o teste exato de Fischer foram utilizados quando apropriados. O teste $t$ foi aplicado para avaliar diferenças entre médias.

\section{RESUITADOS}

A média de idade dos "meninos de rua" $(14,3)$ foi, estatisticamente, maior do que a dos "meninos na rua" $(13,3)$ (teste $t=3,82$, $\mathrm{p}<0,01)$. Referente ao sexo, observou-se a razão de 30:1 do sexo masculino em relação ao feminino na categoria na rua, enquanto esta razão era de aproximadamente 2:1 nos meninos sem vínculo familiar (de rua).

Com relação ao grau de instrução, constatou-se que $78,0 \%$ dos "meninos na rua" dispunham de no máximo instrução primária e que $83,3 \%$ do grupo "meninos de rua" era constituído de indivíduos sem nenhuma escolaridade ou com apenas o curso primário incompleto. Em termos de renda e habitação, verificou-se que, aproximadamente, um quarto dos "meninos na rua" $(25,2 \%)$ tinha renda e habitação regulares (renda igual ou superior a 2 salários mínimos, morava de aluguel ou em residência própria e dispunha de água tratada). Um percentual de $20,1 \%$ tinha saneamento regular (rede de esgoto, vaso sanitário e filtto caseiro). Os demais não eram servidos por esses instrumentos sanitários.

A Tabela 1, mostra a soroprevalência de anti-VHA total em "meninos de/na rua". Em relação à faixa etária, a prevalência média foi de 90,4 variando de $80,0 \%$ a $92,9 \%$. Não se observou aumento estatístico significante da prevalência por faixa etária. Com referência às demais variâveis como: sexo, vínculo familiar, grau de instrução, renda, habitação e saneamento, observaram-se prevalências variáveis entre $82,5 \%$ e $100 \%$, sem diferenças estatísticas significantes.

Os resultados de prevalência no grupo "meninos de/na rua" foram estratificados por vínculo familiar e faixa etária a fim de comparar a soropositividade entre os meninos 
Queiróz DAO, Cardoso DDP, Martelli CMT, Martins RMB, Porto SOB, Azevedo MSP, Borges AMT, Daber RR. Soroepidemiologia da infecção pelo vírus da bepatite A em "meninos de/na rua" de Goiânia - Goiás. Revista da Sociedade Brasileira de Medicina Tropical 28:199-203, jul-set, 1995.

na rua e de rua. Entretanto, as prevalências foram muito próximas e não evidenciaram diferença estatística significante em relação a vínculo familiar ou faixa etária (Figura 1).

\begin{tabular}{|c|c|c|c|}
\hline Variáveis & $\mathrm{N}^{2}+/$ TOTAL & $(\%)$ & $x^{2}$ e valor de $p$ \\
\hline \multicolumn{4}{|l|}{ Sexo } \\
\hline masculino & $326 / 362$ & $(91,2)$ & \multirow[t]{2}{*}{$\mathrm{p}=0,55^{\mathrm{a}}$} \\
\hline feminino & $33 / 35$ & $(94,3)$ & \\
\hline \multicolumn{4}{|l|}{ Vinculo familiar } \\
\hline Na Rua & $282 / 313$ & $(90,1)$ & \multirow{2}{*}{$\begin{array}{c}x^{2}=0,19 \\
p=0,66\end{array}$} \\
\hline De Rua & $77 / 84$ & $(91,7)$ & \\
\hline \multicolumn{4}{|l|}{ Faixa etária } \\
\hline $7-10$ & $28 / 32$ & $(87,5)$ & \multirow{4}{*}{$\begin{array}{c}\mathrm{x}^{2}{ }_{1}=0,8 \mathrm{~b} \\
\mathrm{p}=0,38\end{array}$} \\
\hline $11-14$ & $231 / 251$ & $(92,9)$ & \\
\hline $15-18$ & $92 / 104$ & $(88,5)$ & \\
\hline $19-21$ & $8 / 10$ & $(80,0)$ & \\
\hline \multicolumn{4}{|l|}{ Grau de instruçãa } \\
\hline nenhum & $33 / 40$ & $(82,5)$ & \multirow{5}{*}{$\begin{array}{c}x^{2}{ }_{1}=0,6 b \\
p-0,45\end{array}$} \\
\hline primário incompleto & $220 / 239$ & $(92,0)$ & \\
\hline primário completo & $38 / 44$ & $(86,3)$ & \\
\hline ginásio incomp./completo & $62 / 68$ & $(91,2)$ & \\
\hline $2^{\circ} \mathrm{Grau}$ incompleto & $6 / 6$ & $(100,0)$ & \\
\hline \multicolumn{4}{|l|}{ Renda e habitação } \\
\hline regular & $71 / 79$ & $(89,9)$ & $x^{2}=0,04$ \\
\hline precária & $288 / 318$ & $(90,6)$ & $p=0,85$ \\
\hline \multicolumn{4}{|l|}{ Saneamento } \\
\hline regular & $55 / 63$ & $(87,3)$ & $x^{2}=0,85$ \\
\hline precário & $304 / 334$ & $(91,0)$ & $p=0.36$ \\
\hline
\end{tabular}

$\mathrm{a}=$ Teste de Fischer; $\mathrm{b}=\mathrm{x}^{2}$ para tendência, $\mathrm{gl}=1$

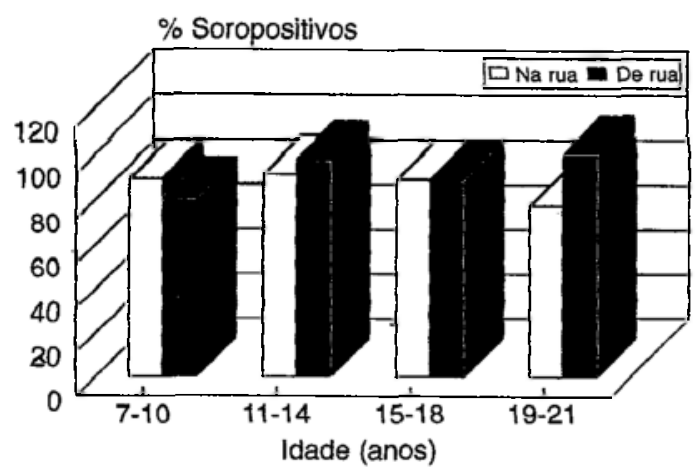

Figura 1 - Soroprevalência de anticorpos anti-VHA total por faixa etária em "meninos delna rua" de Goiânia Goíás.

\section{DISCUSSÃO}

A prevalência de $87,5 \%$ do anti-VHA total observada na faixa etária dos 7-10 anos indica que já no final da primeira década de vida quase não há indivíduos susceptíveis de adquirir a infecção pelo VHA. Esta observação é concordante com o padrão proposto para países como o Brasil'. Nossos resultados estão muito próximos dos observados em São Paulo, que referiram $100 \%$ de soropositividade ao anti-VHA em crianças de 8 anos, de baixo poder aquisitivo, e $87,1 \%$ em indivíduos de 1620 anos, pertencentes ao nivel sócioeconômico médio ${ }^{17}$. Assemelham-se também aos encontrados na Amazônia, que mostraram $83,6 \%$ em indivíduos de 5-9 anos, 100\% nos acima de 10 anos e, no mesmo estudo, outros $80,6 \%$ em indivíduos de $10-14$ anos provenientes de outras localidades, próximas da citada, inclusive aldeias ${ }^{2}$. Também não parecem diferentes dos $90 \%$ encontrados em crianças de 11 anos de Nova Iguaçu (RJ) ${ }^{1}$.

Todavia, estes dados diferem dos resultados observados em estudantes universitários com idade média de 21 anos, no Rio de Janeiro, que mostraram prevalências variando de $38,0 \%$ a $79,6 \%{ }^{16}$. Portanto, a despeito de os universitários serem mais velhos do que os "meninos de/na rua", eles apresentaram menor prevalência. Entretanto, a literatura mostra claramente que a infecção pelo VHA está diretamente relacionada à condição sócio-econômica da população 7151721 . Também há referência de declínio na prevalência do marcador em países que implementaram melhorias no padrão de vida da população 81011 .

Em relação a outros países, com condições melhores que as brasileiras, nossos dados diferem dos já encontrados na Islândia, que referiram $1,6 \%$ de soropositividade ao antiVHA na adolescência ${ }^{3}$; do Canadá, onde observaram $4 \%$ e $10 \%$ em indivíduos de 10 e 16 anos, respectivamente ${ }^{6}$ e do Japão, onde mostraram $10 \%$ em indivíduos de até 14 anos de idade $^{14}$. Também, mais recentemente, referiram $6 \%$ para crianças de $6-7$ anos na Tailândia ${ }^{12}$ e ainda, 1,9\% e 9,5\% em crianças de 6-8 anos e em indivíduos de 3-19 anos, respectivamente, na Itália ${ }^{519}$.

Os índices de prevalência não mostraram nenhuma associação com instrução escolar, renda familiar e habitação ou saneamento $(p>0,05)$, diferente do observado na Itália ${ }^{19} \mathrm{e}$ em Taiwan ${ }^{4}$. Devemos ressaltar, entretanto, que a população de "meninos de/na rua" apresentou-se bastante homogênea do ponto de vista sócio-econômico, o que difere dos dois estudos acima mencionados, realizados em 5 regiões distintas. 
Queiróz DAO, Cardoso DDP, Martelli CMT, Martins RMB, Porto SOB, Azevedo MSP, Borges AMT, Daher RR. Soroepidemiologia da infecção pelo virus da bepatite A em "meninos de/na rua" de Goiânia - Goiás. Revista da Sociedade Brasileira de Medicina Tropical 28:199-203, jul-set, 1995.

Apesar de os "meninos de rua" não possuirem vínculo familiar e estarem na categoria de vida precária, as prevalências não se mostraram diferentes das observadas para aquele percentual de "meninos na rua" que dispunham de condição de vida regular e também de vínculo com a família. Assim, inferimos que higiene pessoal e educação sanitária devem ser precárias nos dois grupos.

Nossa investigação mostra prevalências do marcador de imunidade em um segmento populacional de baixa renda. Tendo em vista a liberação comercial da vacina de vírus inativado (HAVRIX $\left.{ }^{t m}\right)^{13}$ e a execução de vacina de vírus atenuado, outros estudos soroepidemiológicos se fazem necessários para que se possa avaliar o grau de infecção do VHA em população infantil de outras camadas sociais e também definir grupos de risco que deverão, no futuro, serem vacinados em nosso país.

\section{SUMMARY}

A cross-sectional study was performed to determine the age-prevalence of bepatitis $A$ virus (HAV) among street youth from Goiania city Central Brazil, and to determine if any risk factors could be identified. The surveys were conducted between 1991/1992. The street youth were 397 individuals aged 7 to 21 years old living in institutions and teenagers working at streets. Then, 313 adolescents working at streets and with family links, and 84 institutionalized ones without family were screened for antibodies against HAV. Prevalences ranged from $80.0 \%$ to $92.2 \%$ to total anti-HAV and there was not a statistically significant trend of positivity with age in this group. Unvariate analysis for risk factors associated with HAV infection was performed with no statistically significant difference for adolescents working at streets and living with parents, and street youth with family links. Economic variables were not statistically associated with seropositivity, probable due to bomogenous characteristics of the group. This study disclosed that street youth bave a bigb rate of $H A V$ infection. These findings do not suggest differences between subgroups of populations in acquiring immunity to HVA. The public bealtb implication and the need of screening other subgroups of population of the same city were suggested in order to discuss vaccine strategy in underdeveloped countries.

Key-uords: Hepatitis A. Seroepidemiology. Street youth.

\section{REFERÊNCIAS BIBLIOGRAFICAS}

1. Abuzwaida ARN, Sidoni M, Yoshida CFT, Schatzmayr HG. Seroepidemiology of hepatitis A and $B$ in two urban communities of Rio de Janeiro, Brazil. Revista do Instituto de Medicina Tropical de São Paulo 29:219-223,1987.

2. Bensabath G, Hadler SC, Soares MCP, Fields H, Maynard JE. Caracteristicas serologicas $y$ epidemiologicas de la hepatitis virica aguda en la cuenca amazonica del Brasil. Boletin de la Oficina Sanitaria Panamericana 103:351-362,1987.

3. Briem H, Weiland O, Fridriksson I, Berg R. Prevalence of antibody to hepatitis A in Iceland in relation to age, sex, and number of notified cases of hepatitis. American Journal of Epidemiology 116:451-455, 1982.

4. Chen CJ, You SL, You SL, Lu CF, Hsu ST. Seroepidemiology of hepatitis A, B and D viruses among children in Taiwan. In Viral hepatitis and hepatocellular carcinoma, eds Sung JL, Chen DS. Taipei p.9-15,1990.

5. Chiaramante $M$, Moschen ME, Stroffolini $T$, Rapicetta M, Bertin T, Renzulli G, Ngatchu T, Chionne P, Trivello R, Nacarrato R. Changing epidemiology of hepatitis A virus (HAV) infection: a comparative seroepidemiological study (1979 vs 1989) in northeast Italy.The Italian Journal of Gastroenterology 23:344-346,1991.

6. Crewe MD, Embil JA, Garner JB. Prevalence of antibodies to hepatitis A virus in Nova Scotia children. Canadian Medical Association Journal 128:1195-1 197, 1983.

7. Deinhardt F. Prevention of viral hepatitis A: past, present and future. Vaccine 10(suppl 1):S10S14,1992.

8. Green MS, Tsur S, Slepon R. Sociodemographic Factors and the Declining Prevalence of AntiHepatitis A Antibodies in Young Adults in Israel: Implications for the New Hepatitis A Vaccines. International Journal of Epidemiology 21:13641,1992 .

9. Hadler SC. Global Impact of Hepatitis A Virus Infection Changing Patterns. In Viral hepatitis and liver disease, eds Hollinger FB, Lemon SM, Margolis HS. (Williams \& Wilkins). Baltimore p.1420,1991.

10. Hsu HY, Chang MH, Chen DS, Lee CY, Sung JL. Changing Seroepidemiology of hepatitis A Virus Infection in Taiwan. Journal Medical Virology 17:297-301,1985. 
Queiróz DAO, Cardoso DDP, Martelli CMT, Martins RMB, Porto SOB, Azevedo MSP, Borges AMT, Daber RR. Soroepidemiologia da infecção pelo vírus da bepatite A em "meninos delna rua" de Goiânia - Goiás. Revista da Sociedade Brasileira de Medicina Tropical 28:199-203, jul-set, 1995.

11. Hu M, Schenzle D, Deinhardt F, Scheid R. Epidemiology of hepatitis A and B in the Shanghai area: Prevalence of serum markers. American Journal of Epidemiology 120:404-413,1984.

12. Innis BL, Snitbhan R, Hoke CH, Munindhorn W, Laorakpongse $\mathrm{T}$. The Declining Transmission of Hepatitis $A$ in Thailand. Journal of Infectious Diseases 163:989-995,1991.

13. International Symposium on Active Immunization Against Hepatitis A: Worlds' first hepatitis A vaccine introduced at Vienna symposium. Hollinger FB, André FE, Melnick J. (eds) Vaccine 10(suppl 1):S1-\$9,1992.

14. Kashiwagi S, Hayashi J, Ikematsu H, Kusaba T, Shingu T, Hayashida $\mathrm{K}$, Kaji $M$. Prevalence of antibody to hepatitis $\mathrm{A}$ virus in Okinawa and Kyushu, Japan.American Journal of Epidemiology 117:55-59,1983.

15. Mele A, Pasquini P, Pana A. Hepatitis A in Italy: epidemiology and suggestions for control. The Italian Journal of Gastroenterology 23:341$343,1991$.

16. Oliveira LHS, Yoshida CFT, Monteiro SS, Câmara FP. Seroepidemiologic Survey for hepatitis A and $B$ markers in health care students from a Public University of Rio de Janeiro, Brazil. Revista de Microbiologia de São Paulo 22:226-231,1991.

17. Pannuti CS, Mendonça JS, Carvalho MJM, Oselka GW, Amato Neto V. Hepatitis A antibodies in two socioeconomically distinct populations of São
Paulo, Brazil. Revista do Instituto de Medicina Tropical de São Paulo 27:162-164,1985.

18. Queiróz DAO. Soroepidemiologia da infecção pelo vírus da hepatite $A$ em crianças de creche $e$ "meninos de/na rua" de Goiânia-Goiás. Tese de Mestrado, Universidade Federal de Goiás, Goiânia, GO, 1993.

19. Stroffolini T, Chiaramonte M, Franco E, Rapicetta M, Demattia D, Mura I, Trivello R, Giammanco A, Rigo B, Scarpa B. Baseline seroepidemiology of hepatitis A virus infection among children and teenagers in Italy. Infection 19:97-100,1991.

20. Voller A, Bartlett A, Bidwell DE. Enzyme immunoassays with special reference to Elisa techniques. Journal of Clinical Pathology 31:507520,1978 .

21. Vranckx R, Muylle L. Hepatitis A virus antibodies in Belgium: Relationship between prevalence and age. Infection 18:3646,1990.

22. Yoshida CFT, Nogueira RMR, Mercadante LAC, Pinhão AT, Schatzmayr HG. Seroepidemiological survey of hepatitis A and B Cytomegalovirus and Herpes simplex type 2 in prime blood donors from Rio de Janeiro, Brazil. Revista de Microbiologia de São Paulo 18:5-11,1987.

23. Zuckerman AJ. Hepatitis 2000. In: Hollinger FB, Lemon SM, Margolis HS (eds) Viral hepatitis and liver disease. Williams \& Wilkins, Baltimore p. 894897, 1991. 